\title{
Enfisema pulmonar intersticial persistente en recién nacido. Caso clínico
}

\author{
GERMAN MÜHLHAUSEN M. ${ }^{1}$, SCARLETT BRETHAUER M. ${ }^{2}$, \\ FERNANDO MARTÍNEZ R. ${ }^{3}$, YORKY MELIPILLÁN A. ${ }^{4}$ \\ 1. Neonatólogo, Jefe de Servicio Neonatología, Hospital San José. Profesor Asociado Facultad de Medicina Universidad \\ de Chile. \\ 2. Becada Neonatología, Servicio Neonatología, Hospital San José. \\ 3. Broncopulmonar Infantil, Servicio de Enfermedades Respiratorias, Hospital Roberto del Río. \\ 4. Radióloga Infantil. Servicio Radiología, Hospital Roberto del Río.
}

\begin{abstract}
Persistent interstitial pulmonary emphysema in the newborn: clinical case

Persistent Interstitial Pulmonary Emphysema (PIPE) is a syndrome characterized by air leak to the perivascular tissue in the lung, affecting newborns with history of mechanical ventilation. It is also characterized by lack of reabsorption of air in the gap in some areas and giant cell formation. Case Report: A 35-week preterm newborn is presented. Moan and retraction were observed, with oxygen requirements. At the hospital, the diagnosis of transient respiratory distress syndrome was done, requiring nasal CPAP support. At 12 hours of life a sudden clinical deterioration was noted, and a tension pneumothorax of the right lung was confirmed. Pneumothorax was drained with chest tube and high frequency ventilation was initiated. A chest X-ray showed reexpansion of right lung and greater confluence baseline images suggesting bronchopneumonia. After discontinuing ventilatory support, 2 chest CT images show a persistent interstitial pulmonary emphysema in the right lung. Patient was discharged at 13 days of life. Discussion: PIPE is a syndrome that must be suspected within the differential diagnosis of cystic lung diseases in the newborn. Its identification allows the exclusion of similar entities, and avoid unnecessary surgeries since PIPE may lead to spontaneous resolution.
\end{abstract}

(Key words: Persistent pulmonary emphysema interstitial, newborn, pneumothorax).

Rev Chil Pediatr 2012; 83 (1): 73-77

\section{RESUMEN}

El enfisema pulmonar intersticial persistente (EPIP) es un síndrome que se caracteriza por escape aéreo del tejido perivascular del pulmón afectando a recién nacidos (RN) con antecedentes de ventilación mecánica. Caso clínico: RN pretérmino de 35 semanas AEG producto de cesárea que evoluciona con quejido y retracción requiriendo oxigenoterapia. Se hospitaliza con diagnóstico de síndrome de dificultad respiratorio transitorio, requiriendo apoyo con CPAP nasal. A las 12 horas de vida presenta brusco deterioro clínico, causado por un neumotórax a tensión del pulmón derecho el cual se drena con tubo pleural y se conecta a ventilación de alta

Trabajo recibido el 03 de agosto de 2011, devuelto para corregir el 22 de septiembre de 2011, segunda versión el 27 de noviembre de 2011, aceptado para publicación el 08 de diciembre de 2011.

Correspondencia a:

German Mühlhausen M.

E-mail: german.muhlhausen@redsalud.gov.cl 
frecuencia. El control radiográfico muestra reexpansión del pulmón derecho, evoluciona favorablemente extubándose al cuarto día, TAC de tórax muestra imágenes pulmón derecho compatibles con un enfisema pulmonar intersticial persistente. Se da de alta a los 13 días de vida. Discusión: El diagnóstico de EPIP se basa principalmente en la sospecha clínica y radiográfica, teniendo el TAC pulmonar un rol fundamental, con imágenes características de líneas centrales gruesas asociadas a grandes puntos rodeados de imágenes radiolúcidas, que corresponden a quistes. El manejo depende de cada caso. La cirugía se reserva según evolución y extensión del enfisema. Conclusiones: La identificación del EPIP nos permite excluir otras entidades parecidas y evitar cirugías innecesarias, ya que la evolución del EPIP puede incluso ir hacia la resolución espontánea.

(Palabras clave: Enfisema pulmonar intersticial persistente, neonato, neumotórax. Distress respiratorio).

Rev Chil Pediatr 2012; 83 (1): 73-77

\section{Introducción}

El enfisema pulmonar intersticial persistente (EPIP) es un síndrome que se caracteriza por escape aéreo en el tejido perivascular del pulmón y que afecta principalmente a recién nacidos (RN) con antecedentes de ventilación mecánica o ventilación a presión positiva. Stocker et al, describe este fenómeno ya en el año 1977, mostrando un estudio retrospectivo de 22 pacientes tratados con oxigenoterapia y/o ventilación mecánica ${ }^{1}$. La incidencia actual descrita es de alrededor de un 2-4\% de los ingresos a unidades intensivas neonatales ${ }^{2,3}$.

Se describe con mayor frecuencia en RN pretérmino, aunque su presentación en $\mathrm{RN}$ de término cada vez es más habitual.

Clínicamente el enfisema intersticial pulmonar se puede clasificar como agudo o persistente, así como también por extensión: localizado (uni o multi lobar) o difuso ${ }^{3,4}$. El EPIP se caracteriza por la falta de reabsorción del aire en el intersticio de algunas áreas, por lo que su manifestación es generalmente de forma localizada ${ }^{2}$.

La ventilación mecánica parece ser el principal factor desencadenante, sin embargo, se describen casos también en recién nacidos sin antecedentes de ésta, en que el diagnóstico se plantea finalmente por lo hallazgos radiográficos y/o histológicos característicos ${ }^{5,6}$.

El objetivo de este reporte es dar a conocer una entidad clínica poco frecuente, pero de gran importancia en el diagnóstico diferencial de malformaciones pulmonares en el neonato.

\section{Caso clínico}

Recién nacido de 35 semanas adecuado para la edad gestacional. Hijo de madre 30 años de edad, multípara de 2, que cursó embarazo controlado, con antecedentes de diabetes gestacional manejada con dieta. Además antecedentes de oligohidroamnios severo, motivo por el cual se decidió interrumpir el embarazo a las 35 semanas, con ecografía doppler normal. Se realizó cesárea por antecedentes maternos de doble cicatriz de cesárea anterior. Nació en buenas condiciones, APGAR 8-9. Peso: 2624 grs. Líquido amniótico sin meconio. Evolucionó con quejido y retracción requiriendo $\mathrm{FiO}_{2}$ hasta 0,5 , por lo que se decidió hospitalizar.

Inicialmente evolucionó como un síndrome de distrés respiratorio transitorio del RN, requiriendo apoyo con CPAP nasal. Hematocrito, hemoglucotest y gases arteriales de las 3 horas de vida resultaron normales. Radiografía de tórax de las 3 horas de vida impresionó como un síndrome de pulmón húmedo (figura 1). Evolucionó con disminución de los requerimientos de $\mathrm{O}_{2}$, pero con retracción subcostal y polipnea mantenida. A las 12 horas de vida presentó brusco deterioro clínico, que resultó en un neumotórax a tensión del pulmón derecho (figura 2). Se drenó con tubo pleural y se conecta a ventilación de alta frecuencia, con parámetros bajos. Control radiográfico posterior mostró reexpansión del pulmón derecho e imágenes basales derechas de mayor confluencia que impresionaban como bronconeumonia. Hemograma y PCR resultarón normales. Se 


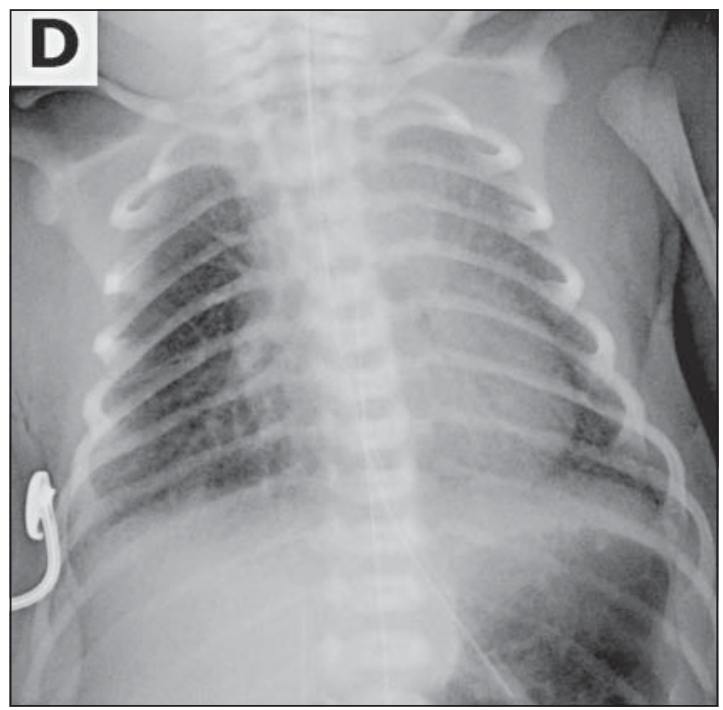

Figura 1. Radiografía AP que muestra buen volumen pulmonar e imágenes instersticiales que impresionan la evolución de un pulmón húmedo de RN. No se observan escapes aéreos.

decidió iniciar antibióticos de primera línea por descompensación clínica asociada a éstas imágenes, con ampicilina y gentamicina en dosis habituales. Evolucionó estable, disminuyendo los parámetros ventilatorios progresivamente. A las 48 horas de instalado el tubo pleural, se pinzó aumentando levemente el enfisema en el lóbulo superior y medio, por lo que se volvió a abrir. Se repitió screening infeccioso por sospecha clínica de bronconeumonia, pero éste siempre resultó normal. Al cuarto día de vida con parámetros mínimos, se extubó quedando en naricera, volviendo a VAFO por apnea.

Ya al quinto día de evolución, se retiró en forma definitiva del ventilador mecánico, sin distrés posterior ni reaparición del enfisema intersticial. Se suspendió además antibioticoterapia.

Una vez en naricera, aún con tubo de drenaje, se realizó TAC de tórax que mostró grandes quistes del lóbulo superior y medio derecho, con indemnidad del pulmón izquierdo. Se retiró el drenaje y se realizó un segundo control a las 48 horas post retiro del tubo pleural, que no mostró reproducción del enfisema ni mayor compromiso de los quistes, con imágenes del pulmón derecho compatibles con un enfisema

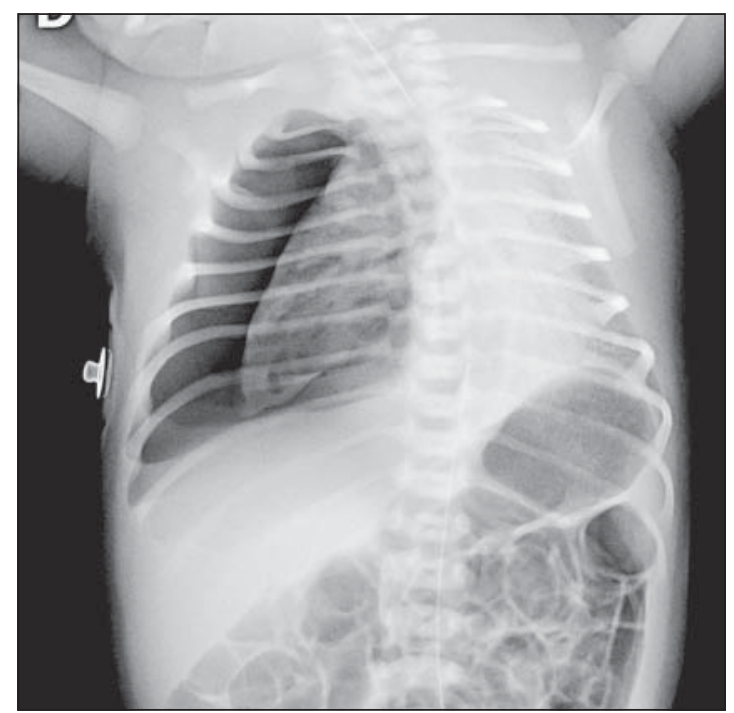

Figura 2. Radiografía AP que muestra gran neumotórax a tensión derecho. No se observan imágenes patológicas en el parénquima contralateral.

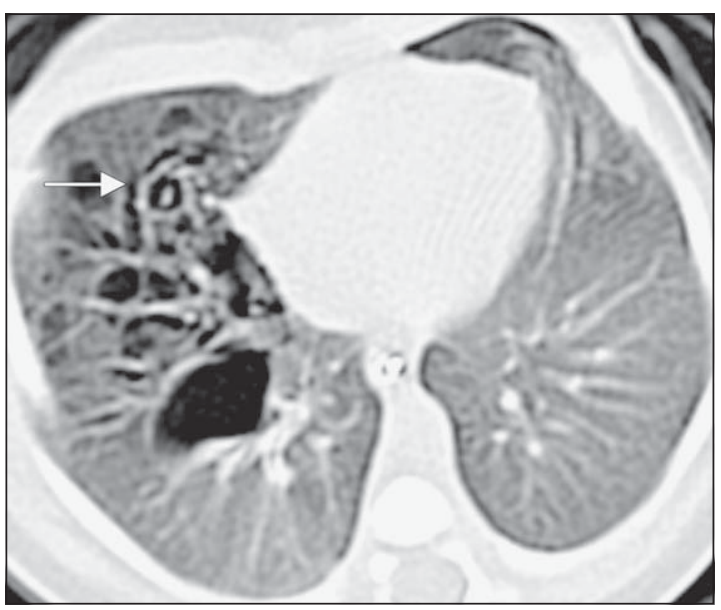

Figura 3. TAC pulmonar que muestra imagen característica de EPIP en corte transversal (flecha).

pulmonar intersticial persistente (figuras $3 \mathrm{y}$ 4). Fue evaluado por un equipo multidisciplinario (cirujanos infantiles, broncopulmonar infantil y radiólogos infantiles), decidiendo manejo expectante. A los 13 días de vida, sin dificultad respiratoria, alimentándose bien al pecho se decidió alta y control ambulatorio por especialistas (figura 5).

Durante su primer año de vida, se ha con- 


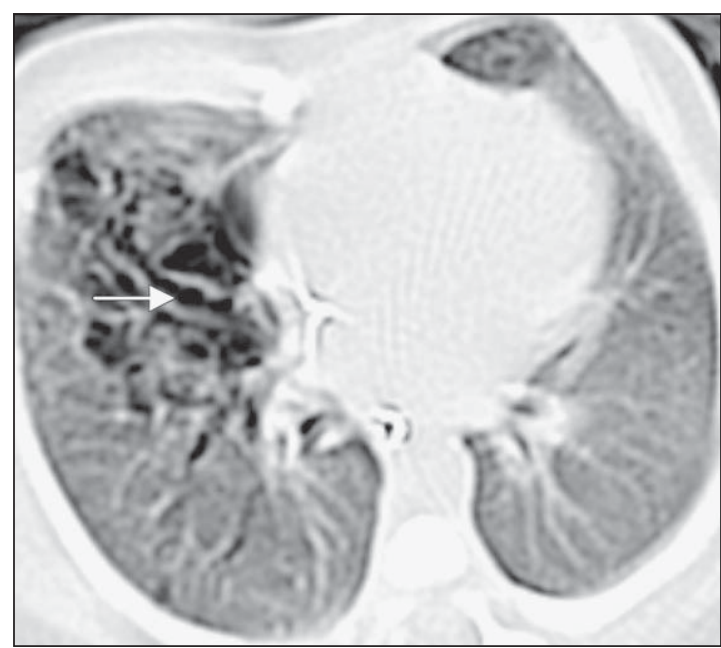

Figura 4. TAC pulmonar que muestra imagen característica de EPIP en corte longitudinal (flecha).

trolado en varias oportunidades por el médico Broncopulmonar Infantil. Ha evolucionado bien sin eventos respiratorios intercurrentes. Sus radiografías de tórax no han mostrado diferencias con la de los 13 días de vida.

\section{Discusión}

El EPIP es un síndrome descrito hace más de 30 años, que debe estar presente dentro de los diagnósticos diferenciales de enfermedades quísticas del pulmón en el recién nacido. El enfisema intersticial es generalmente un fenómeno más bien transitorio, pero en algunas ocasiones, persiste y se extiende. La fisiopatología aceptada es por una disrupción de la membrana basal del alvéolo y lenta reabsorción del aire, quedando éste atrapado en el intersticio lo que gatilla finalmente la formación de bulas gigantes ${ }^{6}$. Los reportes descritos, se relacionan habitualmente con pacientes que cursan con síndromes de distrés respiratorio con necesidad de ventilación mecánica, así como también recién nacidos sin antecedentes de importancia, que ingresan a la unidad de neonatología sin síntomas respiratorios y presentando sólo ictericia ${ }^{1-3,5-7}$.

El diagnóstico se basa principalmente en la sospecha clínica y radiográfica, teniendo la tomografía axial computarizada (TAC) pulmonar un rol fundamental en el diagnóstico dife-

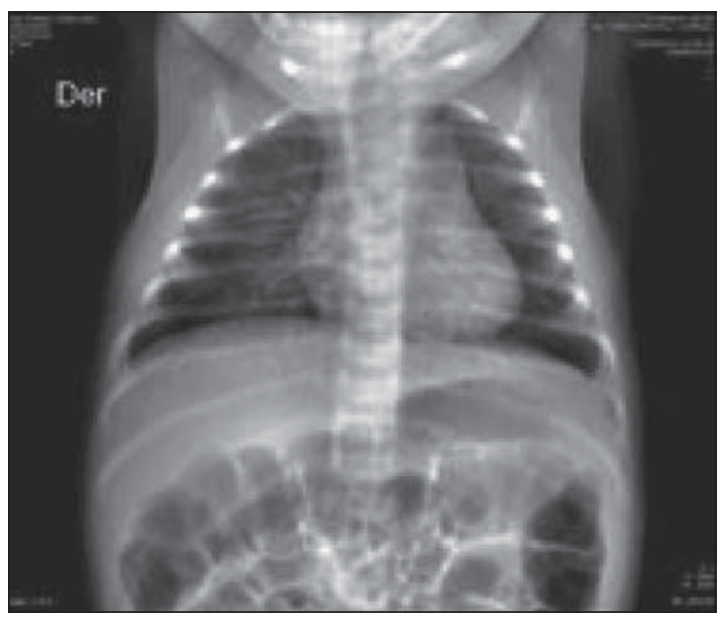

Figura 5. Radiografía AP al mes de vida que sólo muestra imágenes intersticiales bilaterales.

rencial ${ }^{4}$. Donnelly et al, describe una serie de 17 recién nacidos portadores de EPIP, en que el $82 \%$ de las TAC pulmonares mostraron líneas centrales gruesas asociadas a grandes puntos rodeados de imágenes radiolúcidas, que corresponden a quistes, lo que al igual que en otros reportes, se describen como característicos de esta entidad ${ }^{4}$.

El manejo es discutible y va a depender caso a caso. La conducta inicial habitual es expectante, manejándose en ventilación de alta frecuencia y describiéndose como alternativas en el manejo ventilatorio la intubación del bronquio contralateral del EPIP así como también la posición de prono ${ }^{5}$. La cirugía se reserva según evolución y extensión del enfisema. Es por este motivo que considerar el EPIP dentro del diagnóstico diferencial de enfisema lobar congénito, malformación adenomatoidea quística, quistes broncogénicos entre otras, es de gran relevancia, ya que la identificación de este síndrome nos permite excluir las demás entidades y evitar cirugías innecesarias, ya que incluso, la evolución del EPIP puede ir hacia la resolución espontánea ${ }^{6}$.

\section{Referencias}

1.- Stocker JT, Madewell JE: Persistent Intersticial Pulmonary Emphysema: Another Complication of the Respi- 
ratory Distress Syndrome. Pediatrics 1977; 59; 847-57.

2.- Gurakan B, Tarcan A, Arda IS: Persistent Pulmonary Interstitial Emphysema in an Unventilated Neonate. Pediatric Pulmonology 2002; 34: 409-11.

3.- Pursnani SK, Amodio JB, Guo H, Greco MA, Nadler $E P$ : Localized persistent interstitial pulmonary emphysema presentind as a spontaneous tension pneumothorax in a full term infant. Pediatr Surg Int 2006; 22: 613-6.

4.- Donnely LF, Lucaya J, Ozelame V, et al: CT Findings and Temporal Course of Pesistent Pulmonary Intersticial
Emphysema in Neonates: A multiinstitutional Study. AJR: 2003; 180: 1129-33.

5.- Berk DR, Varich LJ: Localized persistent pulmonary interstitial emphysema in a preterm infant in the absence of mechanical ventilation. Pediatr Radiol 2005; 35: 1243-5.

6.- Jassal MS, Benson JE, Mogayzel P: Spontaneous Resolution of Difusse Persistent Pulmonary Interstitial Emphysema.Pediatr Pulmonol 2008; 43: 615-9.

7.- Crosswell HE, Stewart DL: Radiological Case of the month. Arch Pediatr Adolesc Med 2001; 155: 615-6. 